Supporting Information:

\title{
Voltammetric Analysis of Redox Reactions and Ion Transfer in Water Microdroplets
}

Connor K. Terry Weatherly ${ }^{\mathrm{a}}$, Matthew W. Glasscott ${ }^{\mathrm{b}}$, and Jeffrey E. Dick ${ }^{\mathrm{b}, \mathrm{c} *}$

*Corresponding author: jedick@email.unc.edu

${ }^{a}$ Current address: Department of Chemistry, University of Utah, Salt Lake City, UT 84112, United States

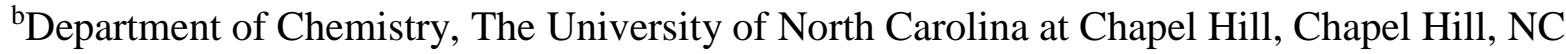
27599, USA

${ }^{c}$ Lineberger Comprehensive Cancer Center, School of Medicine, The University of North

Carolina at Chapel Hill, Chapel Hill, NC 27599, USA

Table of Contents

1. Standardizing $\mathrm{RE}$ against $\mathrm{Fc} / \mathrm{Fc}^{+}$Reaction (Figure S1)

Page

2. Calculation of the Average Droplet Radius by Amperometry and DLS (Figure S3) S-4

3. Calculation of Droplet Collision Frequency

S-6

4. Calculation of Gibbs Free Energy of Ion Transfer (Figure S3)

S-7

5. $\mathrm{H}_{2} \mathrm{O} /$ DCE Galvani Potential Difference and Electrolyte Concentrations (Table S1, S2)

6. Dependence of $E_{1 / 2}$ on the Droplet Radius of Single Microdroplets (Figure S4)

7. Cyclic Voltammograms Trials 3-6 from Figure 4 of the Main Text (Figure S5)

8. Correlated Collisions of Droplets with Ultramicroelectrodes (Figure S6, S7)

9. Finite-Element Simulation of Microdroplet Electrochemistry (Figure S8)

10. Simulated Voltammetry Varying Droplet Radius and Contact Angle (Figure S9)

S-19

11. Simulated Voltammetry Varying the Electron-Transfer Rate Kinetics (Figure S10)

12. Voltammetry of $\mathrm{TBA}_{x} \mathrm{~K}_{3-\mathrm{x}} \mathrm{Fe}(\mathrm{CN})_{6}$ in DCE (Figure S11)

13. Pt Disk Electrode vs Glassy Carbon Disk Electrode in $\mathrm{H}_{2} \mathrm{O}$ with $5 \mathrm{mM}$ Potassium Ferrocyanide. (Figure S12) 


\section{Standardizing $\mathrm{RE}$ against $\mathrm{Fc} / \mathrm{Fc}^{+}$Reaction.}

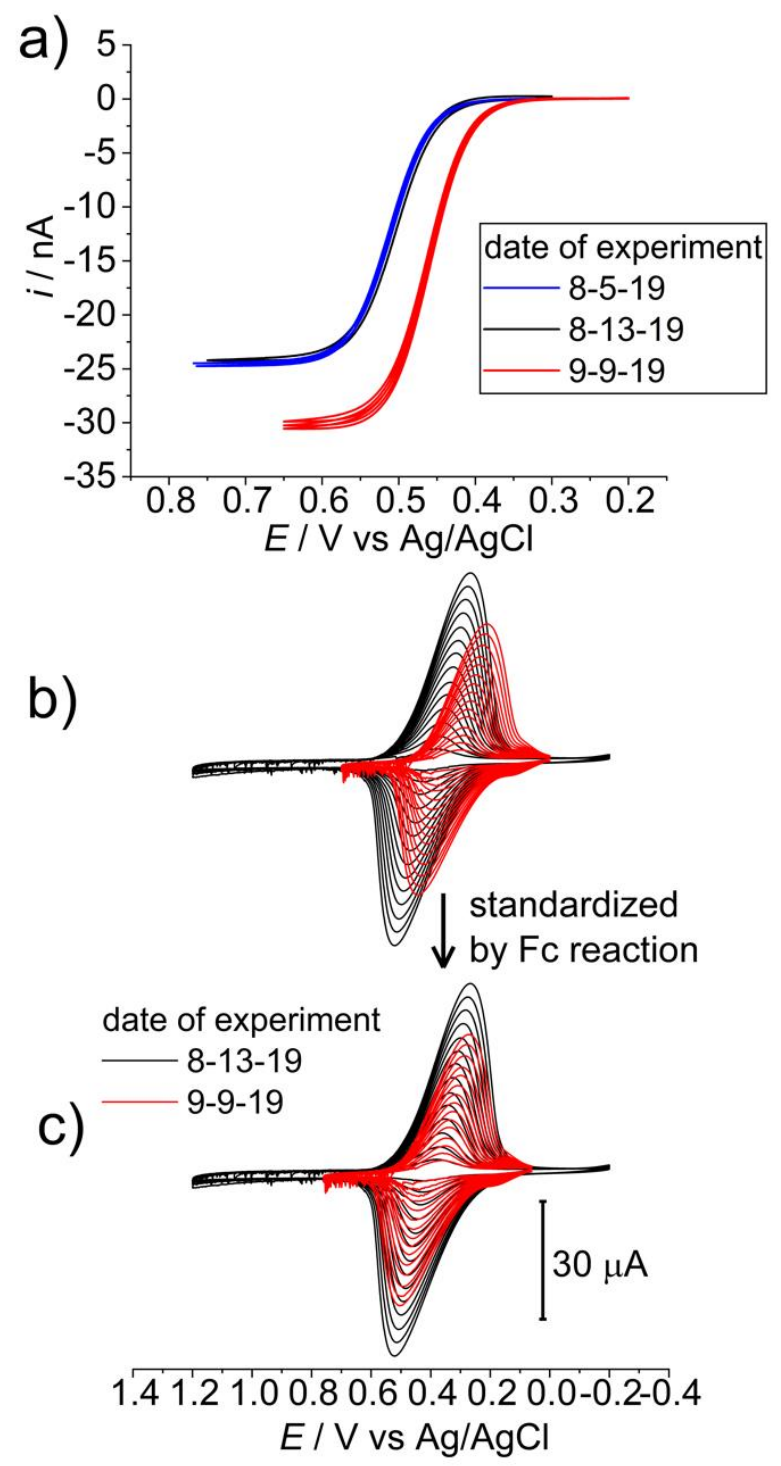

Figure S1. Comparison of cyclic voltammetry on different days using the same RE: $\mathrm{Ag} / \mathrm{AgCl}$ (sat'd $\mathrm{KCl}$ ), as well as the standardization of a voltammetric measurements using the $\mathrm{Fc} / \mathrm{Fc}^{+}$reaction. (a) Cyclic voltammetry with a $\sim 5 \mu \mathrm{m}$ electrode placed, in acetonitrile containing $5 \mathrm{mM} \mathrm{Fc}$. Each curve shows the experiment performed on different days: red curve was run on 9-9-18, black curve was run on 8-13-19, blue curve was run on 8-5-19. The acetonitrile also contained $0.1 \mathrm{M} \mathrm{TBAPF}_{6} . n=100 \mathrm{mV} / \mathrm{s}$. (b) and (c) show the voltemmetric response of an ensemble of $\mathrm{H}_{2} \mathrm{O}$ droplets adsorbed to a glassy carbon electrode $(\sim 1.5 \mathrm{~mm}$ radius) against the $\mathrm{Ag} / \mathrm{AgCl} \mathrm{RE}$, run on 8-13-19 (black) and 9-9-19 (red). (b) Before standardizing using the $\mathrm{Fc} / \mathrm{Fc}^{+}$reaction. (c) After standardizing using the $\mathrm{Fc} / \mathrm{Fc}^{+}$reaction. The DCE phase contained $0.1 \mathrm{M}$ $\mathrm{TBAClO}_{4} \cdot v=100 \mathrm{mV} / \mathrm{s}$.

In this paper, all voltammetric and amperometric measurements were made vs a $\mathrm{Ag} / \mathrm{AgCl}$ (sat'd $\mathrm{KCl})$ reference electrode $(\mathrm{RE})$. The $\mathrm{KCl}$ solution and $\mathrm{Ag} / \mathrm{AgCl}$ wire were contained in a glass cell with a 
vycor frit allowing ions to transport in and out of the RE cell. In the majority of the experiments performed, the RE was placed in an organic solution and the Galvani potential across vycor frit, from the sat' $\mathrm{d} \mathrm{KCl}$ solution to the organic phase, was not known. Some variability was observed in the measured potential, likely due to changes in this vycor frit, such as ions being trapped within it (likely $\left[\mathrm{Fe}(\mathrm{CN})_{6}\right]^{3-}$ or $\left[\mathrm{Fe}(\mathrm{CN})_{6}\right]^{4-}$ since the frit was observed to have a blue color after use in an aqueous $\left[\mathrm{Fe}(\mathrm{CN})_{6}\right]^{4-}$ solution). To overcome this variability, the $\mathrm{Ag} / \mathrm{AgCl} \mathrm{RE}$ was standardized vs the ferrocene/ferocenium $\left(\mathrm{Fc} / \mathrm{Fc}^{+}\right)$reaction.

Before running experiments, voltammetry was performed with a Pt electrode placed in a $5 \mathrm{mM} \mathrm{Fc}$ acetonitrile solution vs the $\mathrm{Ag} / \mathrm{AgCl} \mathrm{RE}$. The half wave potential $\left(E_{1 / 2}\right)$ of the reaction was determined and compared to previous experiments. Any differences in the $E_{1 / 2}$ for the $\mathrm{Fc} / \mathrm{Fc}^{+}$reaction was accounted for when comparing experiments performed on different days. Figure S1a shows a comparison of the $\mathrm{Fc} / \mathrm{Fc}^{+}$ reaction from three different days as an example of this standardization method. The experiment performed on day 8-5-19 (blue) and 8-13-19 (black) both give the same $E_{1 / 2}$ value for the $\mathrm{Fc} / \mathrm{Fc}^{+}$reaction $(0.51 \mathrm{~V})$. The experiment performed on day 9-9-19 (red) showed a large shift in $E_{1 / 2}(-0.06 \mathrm{~V})$ from the other days. Figure $\mathrm{S} 1 \mathrm{~b}$ shows two experiments where an ensemble of $\mathrm{H}_{2} \mathrm{O}$ droplets, containing $50 \mathrm{mM}\left[\mathrm{Fe}(\mathrm{CN})_{6}\right]^{4-}$, were adsorbed to a macro electrode. Both experiments were run vs the $\mathrm{Ag} / \mathrm{AgCl} \mathrm{RE}$. The black curve shows the experiment run on 8-13-19, and the red shows the experiment run on 9-9-19, after the large shift in $E_{1 / 2}$ was observed for the $\mathrm{Fc} / \mathrm{Fc}^{+}$in Figure S1a. The voltammetric wave for the black curve had an $E_{1 / 2}=0.40 \mathrm{~V}$, and the red curve had an $E_{1 / 2}=0.33 \mathrm{~V}$. Figure $\mathrm{S} 1 \mathrm{~b}$ shows the experiments before standardization, and Figure S1c shows after standardization, where the cyclic voltammogram on day 9-9-18 was shifted $+0.06 \mathrm{~V}$. The good comparison between the red curve and the black curve in Figure S1c confirms that standardizing with the $\mathrm{Fc} / \mathrm{Fc}^{+}$reaction is a valid method. 


\section{Calculation of the Average Droplet Radius through Amperometric Measurements and Dynamic Light Scattering}

Figure S2 shows an amperometric measurement with a Pt ultramicroelectrode placed in a water-in-DCE emulsion, where the $\mathrm{H}_{2} \mathrm{O}$ phase contained $\left[\mathrm{Fe}(\mathrm{CN})_{6}\right]^{4-}$ and the electrode was biased to $0.6 \mathrm{~V}$ vs the $\mathrm{Ag} / \mathrm{AgCl} \mathrm{RE}$. The two current-time ( $i$-t) traces in Figure S2a show the current response of droplets colliding with the electrode.

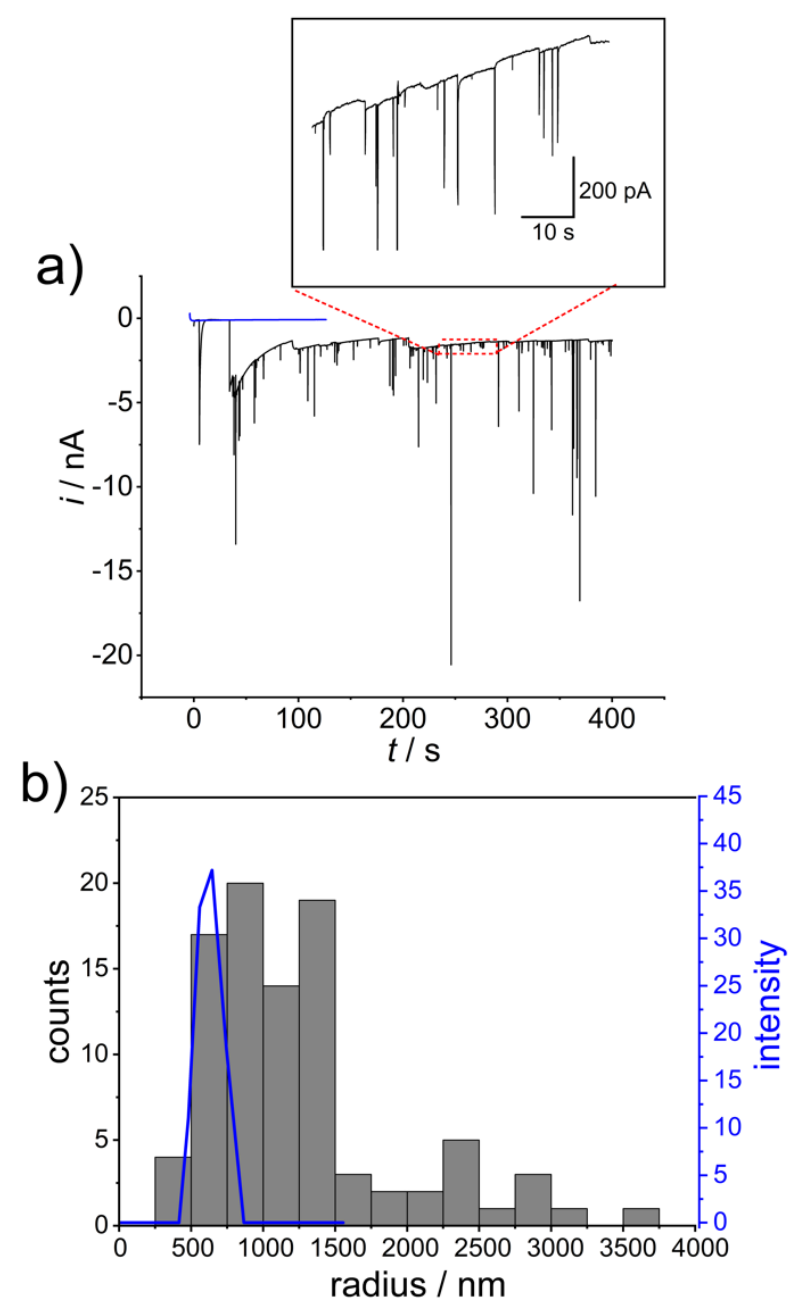

Figure S2. (a) Amperometric measurement with a $10 \mu \mathrm{m}$ radius Pt electrode placed in a water-in-DCE emulsion. The $\mathrm{H}_{2} \mathrm{O}$ phase contained $50 \mathrm{mM} \mathrm{K}_{4}\left[\mathrm{Fe}(\mathrm{CN})_{6}\right]$ and $0.1 \mathrm{M} \mathrm{TBAClO}_{4}$. The electrode was biased at $0.6 \mathrm{~V}$ vs the RE. Inset shows a zoom in of the $i$-t curve. (b) Histogram of the droplet radii for each droplet collision from the $i$-t trace shown in (a), calculated through integration of the current spike. The blue curve shows data from dynamic light scattering of the emulsion, where intensity is plotted vs droplet radius.

The blue curve shows the response when no $\left[\mathrm{Fe}(\mathrm{CN})_{6}\right]^{4-}$ is present in the droplet, and the back curve shows the response when $\left[\mathrm{Fe}(\mathrm{CN})_{6}\right]^{4-}$ is present in the droplets. The inset in Figure S2a shows a zoomed in view 
of the $i$-t curve. Figure S2b shows a histogram of the droplet radius for each collision in the black $i$-t from Figure S2a, along with dynamic light scatter intensity plot showing the distribution of droplet radii.

Integration under the $i$ - $t$ responses in Figure S2a can give the charge $(Q)$ passed when a droplet collides with the UME surface. One can then use Faraday's Law to calculate the radius of the droplet $\left(r_{d r o p}\right)$ :

$$
r_{\text {drop }}=\sqrt[3]{\frac{3 Q}{4 n F C \pi}}
$$

where $n$ is the number of electrons transferred, $F$ is Faraday's Constant, and $C$ is the concentration of $\left[\mathrm{Fe}(\mathrm{CN})_{6}\right]^{4-}$ or $\left[\mathrm{Fe}(\mathrm{CN})_{6}\right]^{3-}$ in the droplet. The bars in Figure S2b indicate a histogram of the sizes calculated by approximately 110 collision events of water droplets filled with $50 \mathrm{mM} \mathrm{K}_{4}\left[\mathrm{Fe}(\mathrm{CN})_{6}\right]$. The normalized frequency is proportional to the number of droplets with that given radius. The electrochemical results overlay fairly well with dynamic light scattering (DLS), which reports droplet radii as a Gaussian function about the average. The average droplet radius from the DLS data was $653 \mathrm{~nm}$ with a poly dispersity index of 0.8. The average radius from the calculated results using Faradays law was $1230 \mathrm{~nm}$, with a standard deviation of $670 \mathrm{~nm}$. The agreement between DLS and the calculated results from Faraday's Law is significant in that it suggests complete electrolysis of the $\left[\mathrm{Fe}(\mathrm{CN})_{6}\right]^{4-}$ contained within the droplets in accordance with previous reports in the literature. The average radius from DLS was lower than the average radius from the amperometric measurement, yet it was still within one standard deviation. The calculated DLS radius being lower than the radius from amperometric data using Faradays law does not suggest that less than complete electrolysis, as this would result in a larger average radius from DLS compared to the amperometric measurement. 


\section{Calculation of Droplet Collision Frequency}

The approximate collision frequency of droplets with the electrode surface can be related to the concentration of droplets in solution by:

$$
f=4 D C r_{U M E} N_{A}
$$

Where $f$ is the frequency in $\mathrm{Hz}, D$ is the diffusion coefficient of droplets, $r_{U M E}$ is the ultramicroelectrode radius, and $N_{A}$ is Avogadro's number. The number of droplets may be approximated by dividing the total aqueous volume $(25 \mu \mathrm{L})$ by the volume of the average droplet radius $\left(1.44 \times 10^{-15} \mathrm{~L}, r_{\text {drop }} \sim 700 \mathrm{~nm}\right.$, from DLS). Dividing this result by Avogadro's number and the combined aqueous/organic volume (5 mL) yield a droplet concentration of $29 \mathrm{pM}$. Droplet diffusion coefficients may be approximated by the StokesEinstein equation:

$$
D=\frac{k_{b} T}{6 \pi \eta r_{d r o p}}
$$

Where $k_{b}$ is the Boltzmann Constant, $T$ is the temperature, $\eta$ is the continuous phase viscosity $\left(8.4 \times 10^{-4} \mathrm{~Pa}\right.$ $\mathrm{s}$ for 1,2-dichloroethane), and $r_{\text {drop }}$ is the radius of the average droplet, which may be obtained by DLS. By this relationship, the diffusion coefficient of a droplet with $r_{\text {drop }}=1230 \mathrm{~nm}$ is $2.1 \times 10^{-13} \mathrm{~m}^{2} \mathrm{~s}^{-1}$. Thus, a frequency of approximately $0.13 \mathrm{~Hz}$ is expected based on diffusion-controlled mass transport of droplets to the electrode surface. The observed frequency from the $i$-t curve in Figure S2a was $0.3 \mathrm{~Hz}$. The observed frequency matches well with the theoretical frequency indicating that the average radius from DLS is a more accurate than the average radius from the amperometric data. The larger radius from the amperometric data would result in a frequency a magnitude lower than what was experimentally observed. 


\section{Calculation of Gibbs Free Energy of Ion Transfer}

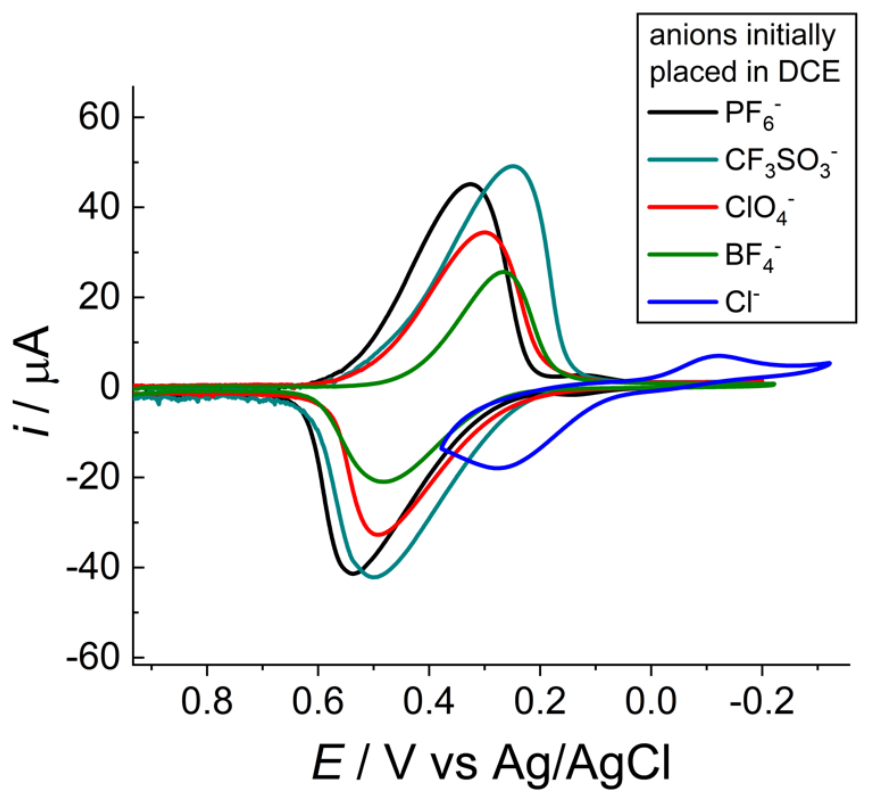

Figure S3. Cyclic voltammetry corresponding to an ensemble of $\mathrm{H}_{2} \mathrm{O}$ droplets adsorbed to a glassy carbon electrode. For each voltammogram the anion in the DCE phase was varied. The black curve corresponds to $0.1 \mathrm{M} \mathrm{TBAPF}_{6}$. The red curve corresponds to $0.1 \mathrm{M} \mathrm{TBACF}_{3} \mathrm{SO}_{3}$. The blue curve corresponds to $0.1 \mathrm{M}$ $\mathrm{TBAClO}_{4}$. The $\mathrm{H}_{2} \mathrm{O}$ phase contained $50 \mathrm{mM} \mathrm{K}$ [ $\left.\mathrm{Fe}(\mathrm{CN})_{6}\right] . v=50 \mathrm{mV} / \mathrm{s}$. The $9^{\text {th }}$ cycle is shown for each voltammogram.

Figure S3 shows voltammograms for an ensemble of droplets adsorbed to the electrode with different electrolyte anions in the DCE phase (only one cycle of each voltammogram is shown). $\mathrm{TBA}^{+}$is kept as the organic electrolyte cation for each experiment . The observed shifts in $E_{1 / 2}$ correspond to changes in the $\mathrm{H}_{2} \mathrm{O} / \mathrm{DCE}$ junction potential due to differences in Gibbs free energy of ion transfer for the different anions. For a single binary electrolyte, with cation $\mathrm{C}^{+}$and anion $\mathrm{A}^{-}$, which completely dissociate, the junction potential between the aqueous and organic phase $(\Delta \varphi)$ can be predicted by the equation: ${ }^{1}$

$$
\Delta \phi^{\mathrm{DCE} \rightarrow \mathrm{H} 2 \mathrm{O}}=\frac{\left(\Delta G_{\mathrm{C}^{+}}^{\mathrm{H} 2 \mathrm{O} \rightarrow \mathrm{DCE}}-\Delta G_{\mathrm{A}^{-}}^{\mathrm{H} 2 \mathrm{O} \rightarrow \mathrm{DCE}}\right)}{2 F}
$$

Where $\Delta G_{\mathrm{C}^{+}}^{\mathrm{H} 2 \mathrm{O} \rightarrow \mathrm{DCE}}$ and $\Delta G_{\mathrm{A}^{-}}^{\mathrm{H} 2 \mathrm{O} \rightarrow \mathrm{DCE}}$ are the Gibbs free energy of ion transfer of the cation and anion, respectively, from $\mathrm{H}_{2} \mathrm{O}$ into DCE, and $F$ is Faradays constant. The organic anion is varied between the voltammograms shown in Figure $\mathrm{S} 3$, and $\mathrm{ClO}_{4}^{-}$is used as a reference anion. The change in junction potential between some anion $\mathrm{A}^{-}$and $\mathrm{ClO}_{4}^{-}$is therefore predicted by the equation:

$$
\Delta \Delta \phi^{\mathrm{DCE} \rightarrow \mathrm{H} 2 \mathrm{O}}=\frac{\left(-\Delta G_{\mathrm{A}^{-}}^{\mathrm{H} 2 \mathrm{O} \rightarrow \mathrm{DCE}}+\Delta G_{\mathrm{ClO}_{4}}^{\mathrm{H} 2 \mathrm{O} \rightarrow \mathrm{DCE}}\right)}{2 F}
$$

Using $\Delta G_{\mathrm{A}^{-}}^{\mathrm{H} 2 \mathrm{O} \rightarrow \mathrm{DCE}}$ values from the literature, see Table $\mathrm{S} 2$, the difference in junction potentials $(\Delta \Delta \phi)$ for $\mathrm{PF}_{6}^{-}, \mathrm{BF}_{4}^{-}$, and $\mathrm{Cl}^{-}$, are $0.032 \mathrm{~V},-0.017 \mathrm{~V},-0.157 \mathrm{~V}$ respectively. The experimentally observed shifts in $E_{1 / 2}$ for the voltammetric waves in Figure $\mathrm{S} 3$ for $\mathrm{PF}_{6}^{-}, \mathrm{BF}_{4}^{-}, \mathrm{Cl}^{-}$, and $\mathrm{CF}_{3} \mathrm{SO}_{3}$ are $0.035 \mathrm{~V},-0.021 \mathrm{~V},-0.362 \mathrm{~V}$, 
and $-0.032 \mathrm{~V}$ respectively. The $\Delta \Delta \phi$ values for $\mathrm{PF}_{6}^{-}$, and $\mathrm{BF}_{4}^{-}$are close to the theoretical values. The $\Delta G_{\mathrm{A}^{-}}^{\mathrm{H} 2 \mathrm{O} \rightarrow \mathrm{DCE}}$ for $\mathrm{CF}_{3} \mathrm{SO}_{3}{ }^{-}$has not been reported in the literature to our knowledge and is calculated to be $\sim 21 \mathrm{~kJ} / \mathrm{mol}$. The voltammetric wave corresponding to the $\mathrm{Cl}^{-}$anion added to the DCE phase shows a large separation between $i_{\mathrm{P}}^{\mathrm{ox}}$ and $i_{\mathrm{P}}^{\text {red }}$. Calculating $E_{1 / 2}$ as the average of these two separated peaks, the difference in junction potential is significantly more negative than the predicted value, however, the potential shift is negative and larger than the $\Delta \Delta \phi$ values for the other anions, which is expected. It is clear the there is a unique phenomenon for TBACl that is not observed with the other anions. One difference is that $\mathrm{Cl}^{-}$has a $\Delta G_{\mathrm{A}^{-}}^{\mathrm{H} 2 \mathrm{O} \rightarrow \mathrm{DCE}}$ value greater than $\Delta G_{\mathrm{TBA}^{+}}^{\mathrm{DCE} \rightarrow \mathrm{H} 2 \mathrm{O}}$, which is not true for the other anions. The other difference is the TBACl is very favorably in the $\mathrm{H}_{2} \mathrm{O}$ phase such that it would partition from the DCE phase into the $\mathrm{H}_{2} \mathrm{O}$ phase reaching saturation. Therefore, during the oxidation of $\left[\mathrm{Fe}(\mathrm{CN})_{6}\right]^{4-}$ the transfer of $\mathrm{Cl}^{-}$into the droplet would supersaturate it, which could cause unique effects compared to the other electrolytes in Figure S3. 


\section{5. $\mathrm{H}_{2} \mathrm{O} / \mathrm{DCE}$ Galvani Potential Difference and Electrolyte Concentrations in Each Phase}

The electrochemical system in each experiment in the main text can be written as:

$\mathrm{Ag} / \mathrm{AgCl}\left|\left(\mathrm{H}_{2} \mathrm{O}\right) \mathrm{K}^{+}, \mathrm{Cl}^{-} \|(\mathrm{DCE}) \mathrm{TBA}^{+}, \mathrm{A}^{-}\right|\left(\mathrm{H}_{2} \mathrm{O}\right) \mathrm{K}^{+},\left[\mathrm{Fe}(\mathrm{CN})_{6}\right]^{4-}$ or $\left[\mathrm{Fe}(\mathrm{CN})_{6}\right]^{3-} \mid \mathrm{GC}$ or Pt electrode Where $\mathrm{A}^{-}$is the anion in the DCE phase. A graphite CE was placed in the DCE phase for experiments when a macro working electrode was used. The $\mathrm{KCl}$ ions in the $\mathrm{Ag} / \mathrm{AgCl} \mathrm{RE}$ solution are highly hydrophilic and will not partition into the DCE phase to any considerable amount. However, when current flows through the RE ions must transfer across the frit, or a double layer is charged at the frit to maintain charge balance. This effect is minimal due to the use of a CE. The anions placed in the organic phase will likely not partition into the RE cell to satisfy equilibrium conditions in the time frame of the measurement, due to slow diffusion in the frit. Therefore, the Galvani potential across the RE frit is not easily determined. We hypothesize that, since the frit does not likely reach its equilibrium Galvani potential, the true Galvani potential across the frit does not vary when changing the organic electrolyte. However, the $\mathrm{H}_{2} \mathrm{O} / \mathrm{DCE}$ Galvani potential always reaches its equilibrium Galvani potential, and is dependent on the organic electrolyte, see below. Therefore, the shifts in $E_{1 / 2}$ observed in Figure S3 are observed because only the $\mathrm{H}_{2} \mathrm{O} / \mathrm{DCE}$ Galvani potential is shifting.

Since the $\mathrm{K}^{+}$and $\left[\mathrm{Fe}(\mathrm{CN})_{6}\right]^{4-} /\left[\mathrm{Fe}(\mathrm{CN})_{6}\right]^{3-}$ are highly hydrophilic and do not leave the $\mathrm{H}_{2} \mathrm{O}$ phase to any considerable amount, the Galvani potential of the $\mathrm{H}_{2} \mathrm{O} / \mathrm{DCE}$ interface in the electrochemical system denoted above, is governed solely by the partitioning of the organic salt ions, $\mathrm{TBA}^{+} \mathrm{A}^{-}$, across the interface, as described by Girualt. ${ }^{1}$ For all the experiments presented herein, the organic anion used was hydrophilic and partitions significantly into the $\mathrm{H}_{2} \mathrm{O}$ phase. The $\mathrm{H}_{2} \mathrm{O}$ /DCE Galvani potential is created by this separation of charged species between the two phases and is given by this equation for a single binary electrolyte which completely disassociates:

$$
\Delta \phi^{\mathrm{DCE} \rightarrow \mathrm{H} 2 \mathrm{O}}=\frac{\left(\Delta \phi_{\mathrm{C}^{+}}^{\mathrm{DCE} \rightarrow \mathrm{H} 2 \mathrm{O}}+\Delta \phi_{\mathrm{A}^{-}}^{\mathrm{DCE} \rightarrow \mathrm{H} 2 \mathrm{O}}\right)}{2}
$$

Using the relationship of Gibbs free energy of ion-transfer to interface potential:

$$
\Delta \phi_{i}^{\circ \mathrm{DCE} \rightarrow \mathrm{H} 2 \mathrm{O}}=\frac{\left(\Delta G_{i}^{\circ \mathrm{H} 2 \mathrm{O} \rightarrow \mathrm{DCE}}\right)}{Z_{i} \mathrm{~F}}
$$

where $\mathrm{F}$ is faradays constant. The equation becomes:

$$
\Delta \phi^{\mathrm{DCE} \rightarrow \mathrm{H} 2 \mathrm{O}}=\frac{\left(\Delta G_{\mathrm{C}^{+}}^{\mathrm{oH} 2 \mathrm{O} \rightarrow \mathrm{DCE}}-\Delta G_{\mathrm{A}^{-}}^{\mathrm{oH}} \rightarrow \mathrm{DCE}\right.}{2 \mathrm{~F}}
$$


This equation is independent of the volume of the two phases as well as the concentration of the electrolyte species. Using the Nernst Equation at ITIES, the partition of the ion $i$ between the DCE and $\mathrm{H}_{2} \mathrm{O}$ phases can be calculated:

$$
\Delta \phi^{\mathrm{DCE} \rightarrow \mathrm{H} 2 \mathrm{O}}=\Delta \phi_{i}^{\circ \mathrm{DCE} \rightarrow \mathrm{H} 2 \mathrm{O}}+\frac{\mathrm{RT}}{\mathrm{F}} \ln \left(\frac{\mathrm{C}_{i}(\mathrm{o})}{\mathrm{C}_{i}(\mathrm{w})}\right)
$$

This equation can be combined with the mass balance equation:

$$
\mathrm{V}_{\mathrm{DCE}} \times \mathrm{C}_{\mathrm{DCE}}^{\mathrm{int}}=\mathrm{V}_{\mathrm{DCE}} \times \mathrm{C}_{\mathrm{DCE}}^{\mathrm{final}}+\mathrm{V}_{\mathrm{H} 2 \mathrm{O}} \times \mathrm{C}_{\mathrm{H} 2 \mathrm{O}}^{\mathrm{final}}
$$

Where $\mathrm{V}_{\mathrm{DCE}}$ and $\mathrm{V}_{\mathrm{H} 2 \mathrm{O}}$ are the volumes of the DCE and $\mathrm{H} 2 \mathrm{O}$ phases, $\mathrm{C}_{\mathrm{DCE}}^{\mathrm{int}}$ is the concentration of ion $i$ before mixing the two phases, and $\mathrm{C}_{\mathrm{DCE}}^{\text {final }}$ and $\mathrm{C}_{\mathrm{H} 2 \mathrm{O}}^{\text {final }}$ are the concentrations of ion $i$ in DCE and $\mathrm{H}_{2} \mathrm{O}$ after mixing the two phases. The combination of equation S9 and equation S10 allow for the calculation of the equilibrium concentrations of the organic electrolyte ions in the two phases. The bulk of the $\mathrm{H}_{2} \mathrm{O}$ and DCE phase are electroneutral and contain equivalent amounts of cations and anions. The excess charge in each phase due to the separation of cations and anions across the liquid/liquid interface resides within nanometers of the $\mathrm{H}_{2} \mathrm{O} / \mathrm{DCE}$ interface creating two sharp ionic layers on either side of the interface. ${ }^{2}$

\begin{tabular}{|ccc|}
\hline Species, $i$ & $\Delta G_{\text {transfer } i}^{\mathrm{H}_{2} \mathrm{O} \rightarrow \mathrm{DCE}} / \mathrm{mol}^{-1}$ & Reference \\
\hline $\mathrm{TBA}^{+}$ & -21.8 & 2 \\
$\mathrm{TOA}^{+}$ & -66.6 & 3 \\
$\mathrm{ClO}_{4}^{-}$ & 14.5 & 3 \\
$\mathrm{PF}_{6}^{-}$ & 8.7 & 4 \\
$\mathrm{Cl}^{-}$ & 45.3 & 4 \\
$\mathrm{BF}_{4}^{-}$ & 18.2 & 4 \\
\hline
\end{tabular}

Table S1. Gibbs free energies for transfer of ions between water and DCE.

\begin{tabular}{|l|l|l|l|l|}
\hline Electrolyte & Volume: $\mathbf{D C E}, \mathbf{H}_{2} \mathbf{O}$ & $\Delta \boldsymbol{\phi}^{\text {DCE } \rightarrow H_{20}}$ & {$\left[\mathbf{C}^{+}\right],\left[\mathbf{A}^{-}\right]$in $\mathbf{H}_{2} \mathbf{O}$} & {$\left[\mathrm{C}^{+}\right],\left[\mathbf{A}^{-}\right]$in DCE } \\
\hline $\mathrm{TBA}^{+} \mathrm{ClO}_{4}^{-}$ & $5 \mathrm{~mL}, 25 \mu \mathrm{L}$ & $-0.177 \mathrm{~V}$ & $0.040 .1444 \mathrm{M}, 0.0411 \mathrm{M}$ & $0.100 \mathrm{M}, 0.100 \mathrm{M}$ \\
\hline $\mathrm{TBA}^{+} \mathrm{ClO}_{4}^{-}$ & $5 \mathrm{~mL}, 5 \mathrm{~mL}$ & $-0.177 \mathrm{~V}$ & $0.0288 \mathrm{M}, 0.0292 \mathrm{M}$ & $0.0712 \mathrm{M}, 0.0708 \mathrm{M}$ \\
\hline $\mathrm{TBA}^{+} \mathrm{PF}_{6}^{-}$ & $5 \mathrm{~mL}, 25 \mu \mathrm{L}$ & $-0.145 \mathrm{~V}$ & $0.0115 \mathrm{M}, 0.0116 \mathrm{M}$ & $0.100 \mathrm{M}, 0.100 \mathrm{M}$ \\
\hline $\mathrm{TBA}^{+} \mathrm{Cl}^{-}$ & $5 \mathrm{~mL}, 25 \mu \mathrm{L}$ & $-0.335 \mathrm{~V}$ & $0.072 \mathrm{M}, 0.072 \mathrm{M}(\text { Sat'd })^{\dagger}$ & $0.996 \mathrm{M}, 0.996 \mathrm{M}$ \\
\hline $\mathrm{TBA}^{+} \mathrm{BF}_{4}^{-}$ & $5 \mathrm{~mL}, 25 \mu \mathrm{L}$ & $-0.194 \mathrm{~V}$ & $0.0787 \mathrm{M}, 0.0756 \mathrm{M}$ & $0.996 \mathrm{M}, 0.990 \mathrm{M}$ \\
\hline
\end{tabular}

Table S2. Concentrations of electrolyte ions in the DCE and $\mathrm{H}_{2} \mathrm{O}$ phase at equilibrium, and the Galvani potential across the interface. Each electrolyte was initially placed in the DCE phase at a concentration of $0.1 \mathrm{M}$. ${ }^{\dagger}$ This values represents the saturation solubility of $\mathrm{TBACl}$ in the $\mathrm{H}_{2} \mathrm{O}$ phase. The equilibrium concentrations for these salts predicted by the Nerst and mass balance equations $(\mathrm{TBACl}=10 \mathrm{M})$ were higher than their saturation concentrations. 


\section{Dependence of $E_{1 / 2}$ on the Droplet Radius of Single Microdroplets}

The $E_{1 / 2}$ was measured for the voltammetric wave directly after the first droplet collision was observed at a ultramicroelectrode placed in a water-in-DCE emulsion. A $10 \mu \mathrm{m}$ gold (Au) disk electrode was placed in a water-in-DCE emulsion, where the water contained $50 \mathrm{mM}$ potassium ferrocyanide, and the DCE phase contained $0.1 \mathrm{M} \mathrm{TBAClO}$. After the electrode was placed in the emulsion the cyclic voltammetry was immediately started. No faradaic current was observed until an initial droplet collided with the electrode, which caused a transient current spike, followed by a voltammetric wave. Faradays law was used to determine the droplet radius from the collision current spike, which was correlated to the $E_{1 / 2}$ of the voltammetric wave observed directly after the collision spike.
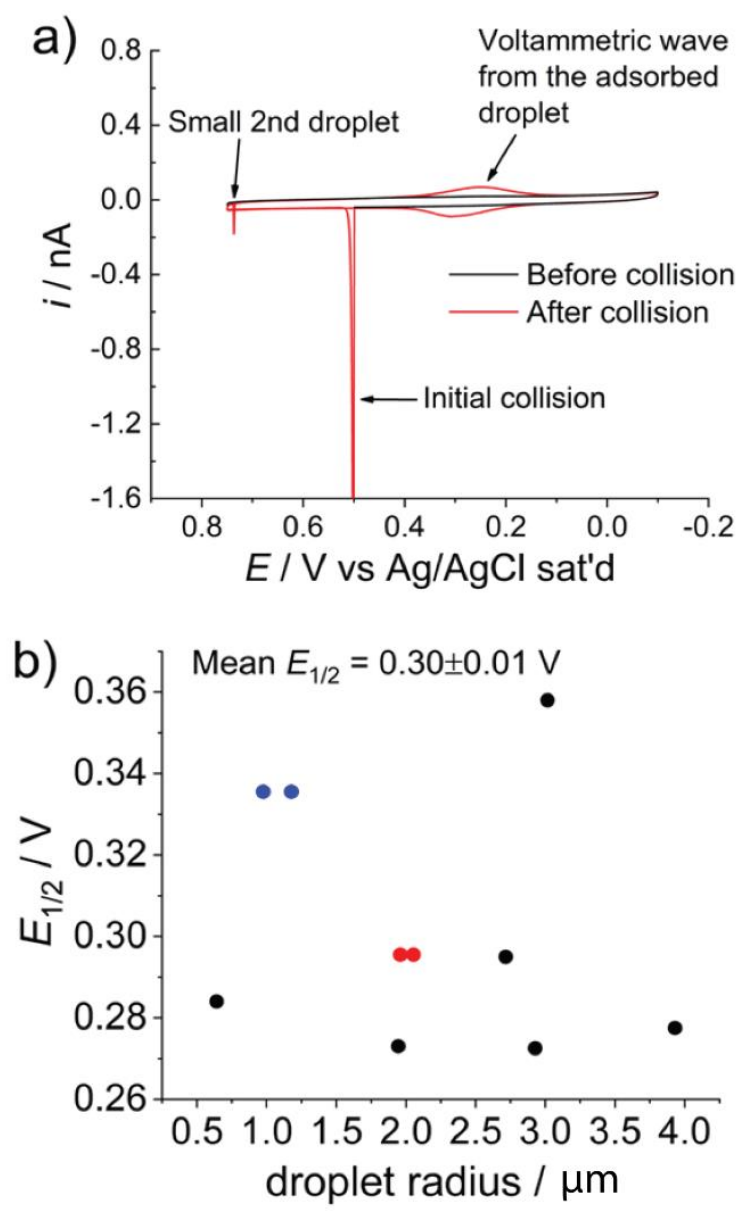

Figure S4. a) Representative cyclic voltammogram showing the first and second droplet collisions with a $10 \mu \mathrm{m}$ Au electrode submerged in a water-in-DCE emulsion, followed by a voltammetric wave. b) Scatter plot showing the dependence of $E_{1 / 2}$ on droplet size. The data points with the same color, blue and red, show data from the same trial. The black data points are from separate trials. The $\mathrm{H}_{2} \mathrm{O}$ phase contained $50 \mathrm{mM}$ $\mathrm{K}_{4}\left[\mathrm{Fe}(\mathrm{CN})_{6}\right]$; the DCE phase contained $0.1 \mathrm{M} \mathrm{TBAClO}_{4} . v=50 \mathrm{mV} / \mathrm{s}$. 
Figure S4a shows a representative cyclic voltammogram where an initial collision was observed followed by a voltammetric wave. The black curve in Figure S4a shows the non-faradaic current response before any droplet had collided with the electrode. The red curve shows the initial collision of a $1.94 \mu \mathrm{m}$ radius droplet colliding with the electrode, followed by a second much smaller droplet colliding with the electrode, followed by a voltammetric wave with an $E_{1 / 2}=0.278 \mathrm{~V}$. The $E_{1 / 2}$ from the voltammetric wave should be correlated to the larger droplet that caused the initial collision. The smaller second droplet would have a smaller voltammetric wave, which is overwhelmed by the larger droplet's voltammetric wave and therefore the $E_{1 / 2}$ of the voltammetric wave would be dominated by the larger droplet. For the cyclic voltammogram shown in Figure $\mathrm{S} 4 \mathrm{a}$, the second droplet was ignored and the $E_{1 / 2}$ value was plotted with the larger droplet's radius in Figure S4b.

Figure $\mathrm{S} 4 \mathrm{~b}$ shows $E_{1 / 2}$ plotted against droplet radius for eight trials, where the electrode was cleaned in between each trial, as described in the materials and methods section of the main text. From these eight trials there was a negligible correlation between $E_{1 / 2}$ and droplet radius (Pearson's r $=-0.21$ ), however, there are issues with this measurement which could have complicated the results. One issue is that due to the frequency of the droplet collisions it was rare to find a trial where only one droplet collided during a cycle. Multiple droplet collisions within a single cycle convolute the $E_{1 / 2}$ value so that it cannot be related to a single droplet size. In an attempt to overcome this, smaller collisions were ignored when a single much larger droplet collision could be related to the $E_{1 / 2}$ of the voltammetric wave, as done in the cyclic voltammogram shown in Figure S4a. If multiple collisions of similar size were observed in a single cycle, they were also used: The data points with the same color, red and blue, are from the same trial, where two collisions with droplets of similar size were observed in close succession. The $E_{1 / 2}$ from the voltammetric wave that followed these two collisions was the same for both of these droplet radii. This is valid because if both of these droplets had similar radii, the $E_{1 / 2}$ should be similar for each, assuming no other confounding factors. Ignoring small droplet collisions and using similar sized droplet collisions allowed for the use of more trials. More sophisticated methods, or more trials, are required to confidently determine the dependence of $E_{1 / 2}$ on droplet radius. 


\section{Cyclic Voltammograms Trials 3-6 from Figure 4 of the Main Text}

Six trials were used in Figure 5 from the main text. The cyclic voltammograms of trial 1 and 2 were shown in this figure. The rest of the full cyclic voltammograms from Figure 5 are shown in Figure S5.
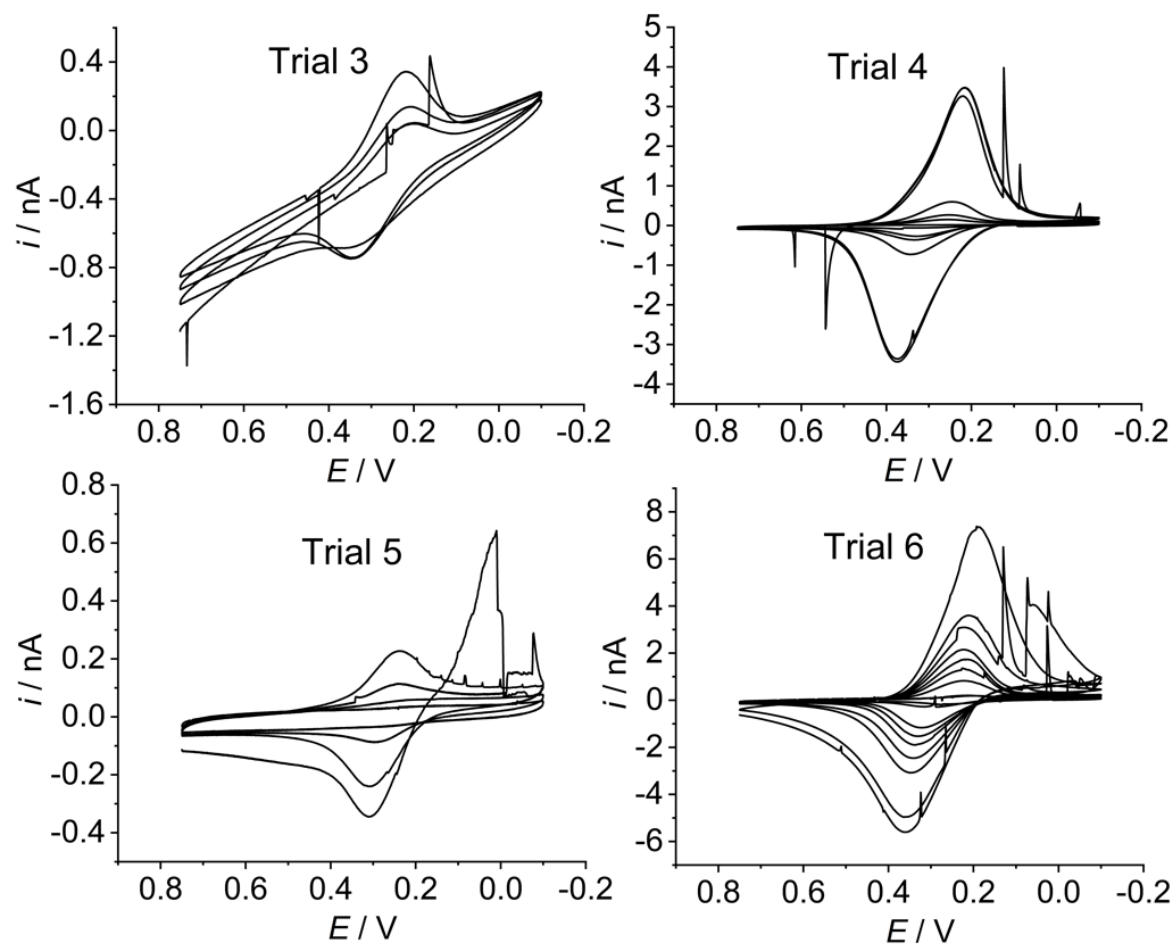

Figure S5. Cyclic voltammetry with a $10 \mu \mathrm{m}$ radius $\mathrm{Pt}$ electrode placed in a $\mathrm{DCE} / \mathrm{H}_{2} \mathrm{O}$ emulsion. The $\mathrm{H}_{2} \mathrm{O}$ phase contained $50 \mathrm{mM}$ potassium ferricyanide; The DCE phase contained $0.1 \mathrm{M} \mathrm{TBAClO}_{4} . v=100$ $\mathrm{mV} / \mathrm{s}$. 


\section{Correlated Collisions of Droplets with Ultramicroelectrodes}

In order to verify that the electrochemical response originates from the collision of single droplets with the ultramicroelectrode and the lifetime of the droplet on the electrode surface, cyclic voltammetry was correlated with fluorescence microscopy of the electrode surface. The results shown in Figure S6 reveals a steady charging current when the electrode is submerged in a solution of 1,2-dichloroethane with $0.1 \mathrm{M} \mathrm{TBAClO} 4$ acting as the supporting electrolyte. When water droplets containing $1 \mathrm{mM}$ fluorescein and $50 \mathrm{mM} \mathrm{K}_{3}\left[\mathrm{Fe}(\mathrm{CN})_{6}\right]$ are introduced, individual droplets may be tracked in solution by the excitation and emission of fluorescein at $490 \mathrm{~nm}$ and $510 \mathrm{~nm}$, respectively. As a droplet collides with the electrode surface, the reduction of the contents is manifested as a sudden spike in the voltammogram, with the reversible redox chemistry of the $\left[\mathrm{Fe}(\mathrm{CN})_{6}\right]^{3-14-}$ couple resulting in a voltammetric wave centered about 0.32 $\mathrm{V}$ vs $\mathrm{Ag} / \mathrm{AgCl}(1 \mathrm{M} \mathrm{KCl})$. Integrating the current response and relating the charge passed to the droplet diameter by Faraday's law closely matches the optically observed droplet diameter of $2 \mu \mathrm{m}$. These data unambiguously show that the electrochemical response results from the collision of single droplets with UMEs.
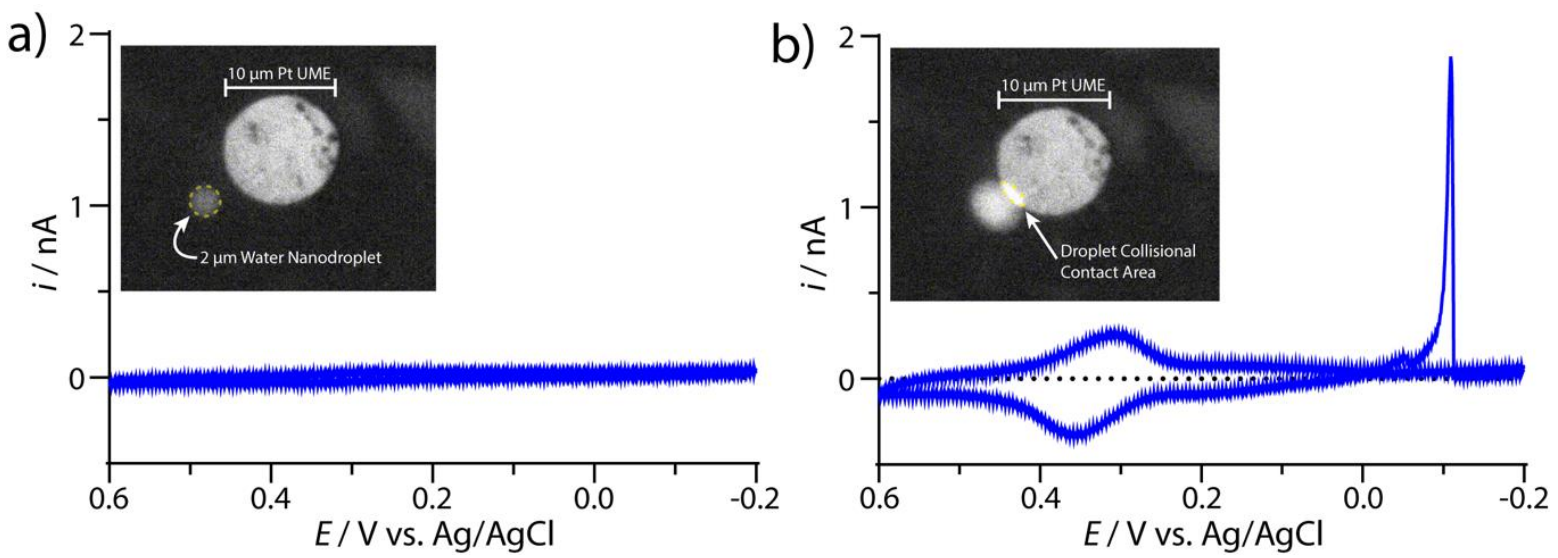

Figure S6. Correlated droplet collisions with optical microscopy. (a) $10 \mathrm{um} \mathrm{Pt} \mathrm{ultramicroelectrode} \mathrm{at} \mathrm{94.5x}$ magnification is approached by a diffusing water droplet loaded with $1 \mathrm{mM}$ fluorescein and $50 \mathrm{mM}$ $\mathrm{K}_{3}\left[\mathrm{Fe}(\mathrm{CN})_{6}\right]$. The background scan shows no appreciable Faradaic activity. (b) Upon droplet collision with the ultramicroelectrode surface at $-0.1 \mathrm{~V}$ during the sweep, the contents are reduced, generating a current spike. The following scan toward the $E_{1 / 2}$ of the $\left[\mathrm{Fe}(\mathrm{CN})_{6}\right]^{3-14-}$ couple shows single droplet redox activity. Fluorophore was excited at $490 \mathrm{~nm}$ with an emission monochromator to the camera held at $510 \mathrm{~nm}$. The DCE phase contained $0.1 \mathrm{M} \mathrm{TBAClO}_{4} . v=100 \mathrm{mV} / \mathrm{s}$.

To further probe the robustness of our understanding of these processes at the nanoscale, Figure S7 shows a finite-element simulation, which was modeled to match an experimental cyclic voltammogram where a $1.66 \mu \mathrm{m}$ radius $\mathrm{H}_{2} \mathrm{O}$ droplet containing $50 \mathrm{mM}\left[\mathrm{Fe}(\mathrm{CN})_{6}\right]^{4-}$ collided with a $10 \mu \mathrm{m}$ radius Pt electrode submerged in a water-in-DCE emulsion. The simulation was treated based completely on diffusion within 
the droplet and Butler-Volmer kinetics were used to described the $\left[\mathrm{Fe}(\mathrm{CN})_{6}\right]^{4-} /\left[\mathrm{Fe}(\mathrm{CN})_{6}\right]^{3-}$ reaction at the electrode surface.

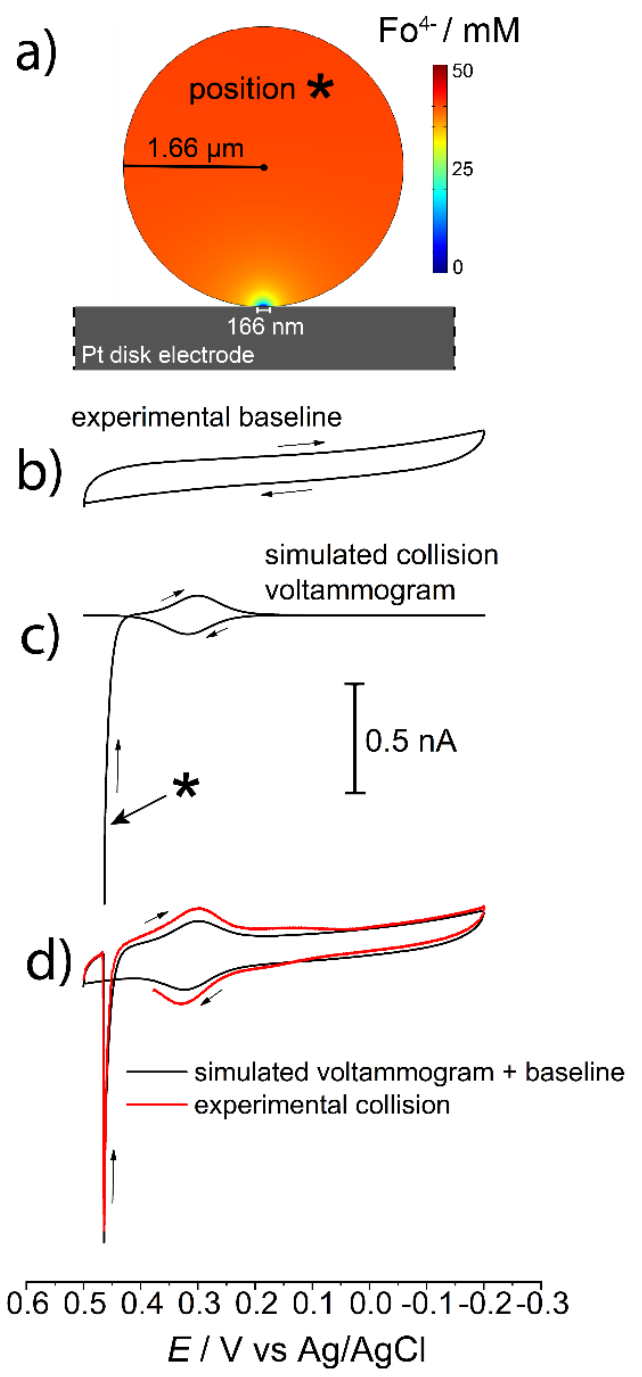

Figure S7. Finite-element simulations of a droplet collision during voltammetry compared to an experimentally observed droplet collision at a $10 \mu \mathrm{m}$ radius $\mathrm{Pt}$ electrode. (a) Two-dimensional concentration profile of a $1.66 \mu \mathrm{m}$ radius droplet containing $\left[\mathrm{Fe}(\mathrm{CN})_{6}\right]^{4-}$. The concentration profile was taken at position * on the simulated voltammogram shown in (c). (b) Experimental voltammogram showing the baseline charging current of a $10 \mu \mathrm{m}$ radius Pt electrode in DCE with $0.1 \mathrm{M} \mathrm{TBAP}$, where no droplets were adsorbed on the electrode. (c) Simulated voltammogram of the droplet model shown in (a) where the starting potential was $0.467 \mathrm{~V}$. (d) The black curve shows the experimental baseline in (b) added with the simulated voltammogram in (c). The red curve shows an experimental voltammogram where a $1.66 \mu \mathrm{m}$ radius droplet, calculated from integration of the collision spike, collided with the electrode. $v=100 \mathrm{mV} / \mathrm{s}$.

Figure $\mathrm{S} 7 \mathrm{a}$ shows the simulated concentration profile of the $1.66 \mu \mathrm{m}$ radius droplet directly after the collision with the electrode (denoted by “*" in Figure S7c). The simulated cyclic voltammogram from this model, Figure S7c, was added with an experimental baseline charging current at the Pt electrode before 
any droplets collided, Figure S7b. The superposition of the experimental baseline current with the simulated cyclic voltammogram resulted in a voltammetric response that matched closely with the experiment collision response (Figure S7d), where the red curve shows the experimental response and the black curve shows the simulation combined with the experimental baseline. The baseline current was taken from the cycle directly before the droplet collided with the electrode.

The $E^{0}$ in the simulation was set as the $E_{1 / 2}$ of the voltammetric wave in the experimental voltammogram $(0.314 \mathrm{~V})$. In the experiment the droplet collided with the electrode at $0.467 \mathrm{~V}$ while sweeping towards negative potentials. Therefore, the simulated voltammogram was started at $0.467 \mathrm{~V}$, with initial conditions of $50 \mathrm{mM}\left[\mathrm{Fe}(\mathrm{CN})_{6}\right]^{4-}$ in the droplet, and was swept towards negative potentials. Since the simulated voltammogram started at a sufficient overpotential all of the $\left[\mathrm{Fe}(\mathrm{CN})_{6}\right]^{4-}$ was quickly oxidized into $\left[\mathrm{Fe}(\mathrm{CN})_{6}\right]^{3-}$ resulting in a transient current decay response matching the collision spike in the experiment. Immediately after this initial oxidation, the $\left[\mathrm{Fe}(\mathrm{CN})_{6}\right]^{3-}$ was reduced back into $\left[\mathrm{Fe}(\mathrm{CN})_{6}\right]^{4-}$ resulting in the reduction peak observed at $0.3 \mathrm{~V}$. On the reverse scan an oxidation peak is observed at 0.33 V from the oxidation of $\left[\mathrm{Fe}(\mathrm{CN})_{6}\right]^{4-}$ back into $\left[\mathrm{Fe}(\mathrm{CN})_{6}\right]^{3-}$. Due to the small size of the droplet, the diffusion of $\left[\mathrm{Fe}(\mathrm{CN})_{6}\right]^{4-}$ to the electrode surface from anywhere in the droplet is fast. The average time it takes for a $\left[\mathrm{Fe}(\mathrm{CN})_{6}\right]^{4-}$ to diffuse the diameter of the droplet is $2.5 \mathrm{~ms}$, calculated by $(2 r)^{2} / 6 D$, where $r$ is the droplet radius and $D$ is the diffusion coefficient of $\left[\mathrm{Fe}(\mathrm{CN})_{6}\right]^{4-}\left(=0.73 \times 10^{-5} \mathrm{~cm}^{2} / \mathrm{s}\right)^{3}$. Therefore, the concentration of the $\left[\mathrm{Fe}(\mathrm{CN})_{6}\right]^{4-}$ in the droplet is nearly homogenous with a small concentration gradient near the electrode surface, as seen in Figure S7a.

The contact area of the electrode in the simulation was varied to best match the experimental voltammetric response. The initial transient current decay, corresponding to the droplet collision, changes drastically depending on the electrode contact area radius, however, the voltammetric wave was nearly independent of the contact area radius (vida infra). The simulation with a contact area radius that was 83 $\mathrm{nm}$ best matched the experimental voltammetric response. Previous reports have attempted to obtain the contact area from bulk electrolysis theory ${ }^{4}$; however, we propose that the COMSOL simulation is more robust. This contact area radius is $1 / 20^{\text {th }}$ the droplet radius. If this ratio of contact area radius to droplet radius is the equilibrium position, then other droplets of various sizes adsorbed to the electrode should have a similar ratio. However, it is possible that the oxidation of $\left[\mathrm{Fe}(\mathrm{CN})_{6}\right]^{4-}$ began before the droplet reached an equilibrium position. It is also possible that the contact area changes depending on the electrode potential. In Figure S6, correlated microscopy showed a droplet collide and stick only partially on the electrode surface. It is possible that this could have also occurred in the experiment in Figure S7. However, the geometry of the contact area likely plays a small role in the current response, compared to the area size. That is, if two droplet/electrode contact areas differ in geometry but have the same area the voltammetric response will be similar. 


\section{Finite-Element Simulation of Microdroplet Electrochemistry}

The voltammetric response of a single spherical droplet placed on an electrode, with a contact area between the electrode and the droplet, was calculated using finite-element modeling. The temporal and spatial concentrations of $\left[\mathrm{Fe}(\mathrm{CN})_{6}\right]^{4-}$ and $\left[\mathrm{Fe}(\mathrm{CN})_{6}\right]^{3-}$ were modeled within the droplet, with the diffusional transport governed by Fick's law:

$$
\frac{\partial C}{\partial t}=D \nabla^{2} C
$$

where $C$ and $D$ are the concentration and diffusion coefficient, respectively. The diffusion coefficients of $\left[\mathrm{Fe}(\mathrm{CN})_{6}\right]^{4-}$ and $\left[\mathrm{Fe}(\mathrm{CN})_{6}\right]^{3-}$ were set as $1 \times 10^{-5} \mathrm{~cm}^{2} / \mathrm{s}$.

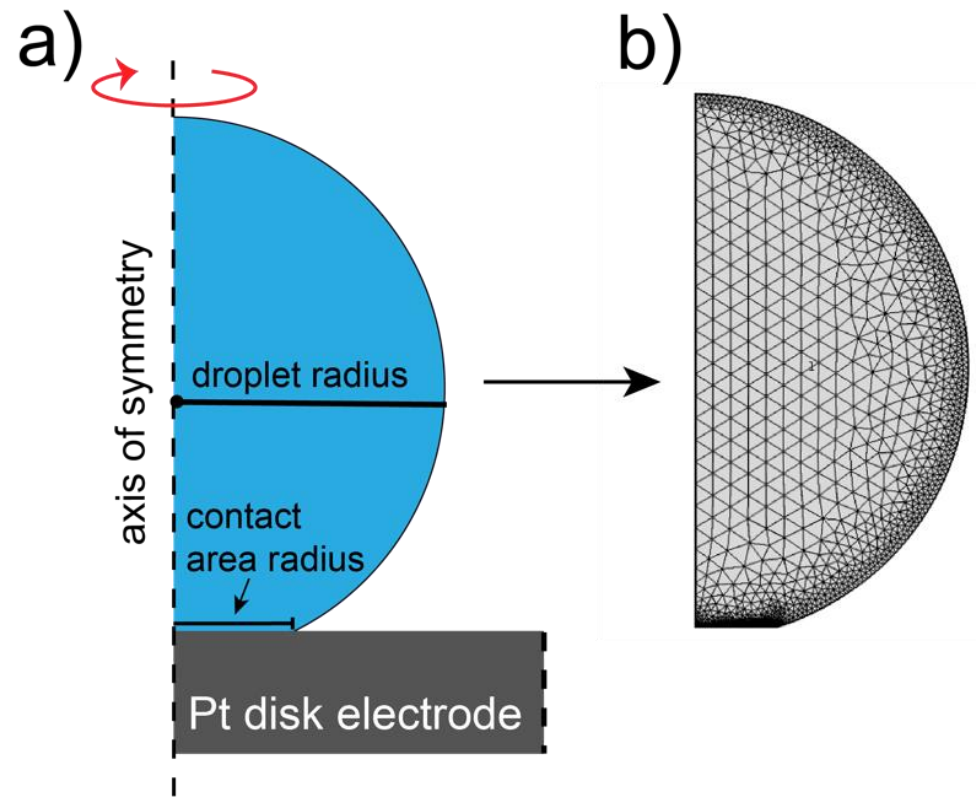

Figure S8. a) Schematic depicting the Comsol model built for simulating single droplet voltammetry. The model was 2D axisymmetric with the vertical dashed line as the axis of symmetry. b) Finite-Element mesh for the model.

The $\left[\mathrm{Fe}(\mathrm{CN})_{6}\right]^{3-14-}$ electron transfer reaction at the electrode $/ \mathrm{H}_{2} \mathrm{O}$-droplet interface were governed by ButlerVolmer kinetics:

$$
J_{\mathrm{Fo}^{4-}}=-J_{\mathrm{Fi}^{3-}}=k_{0}\left(C_{\mathrm{Fo}^{4-}} \exp \left(\frac{\alpha F}{R T}\left(E-E^{0}\right)\right)-C_{\mathrm{Fi}^{3-}} \exp \left(-\frac{(1-\alpha) F}{R T}\left(E-E^{0}\right)\right)\right)
$$


where $E$ is the applied potential, $T$ is the temperature $(295 \mathrm{~K}), \alpha$ is the electron transfer coefficient $(0.5), R$ the molar gas constant, $F$ is Faraday's constant, $k_{0}$ is the heterogeneous rate constant $(0.5 \mathrm{~cm} / \mathrm{s}$, unless stated otherwise), and $E^{0}$ is the standard potential for the $\left[\mathrm{Fe}(\mathrm{CN})_{6}\right]^{4-} /\left[\mathrm{Fe}(\mathrm{CN})_{6}\right]^{3-}$ reaction with a $\mathrm{Ag} / \mathrm{AgCl} \mathrm{RE}$ electrode placed in the DCE phase.

Figure S8a shows a representation of the 2D axisymmetric Comsol model used to calculate the voltammetric response as well as the mesh used in the discretization of the model. The Pt disk electrode was drawn in for clarity. The droplet geometry was created as a perfect circle with the bottom cut off representing the electrode.

The current response $(i)$ was calculated by integrating the diffusional flux of $\left[\mathrm{Fe}(\mathrm{CN})_{6}\right]^{4-}$, normal to the electrode surface, over the entire electrode:

$$
i=F \int_{\text {elec }} J_{\mathrm{Fo}^{4-}}
$$

Comsol Multiphysics calculates this solution in cylindrical coordinates such that the solution is correct for the 3D model, created by the rotation of the 2D model around the axis of symmetry. This current response, as calculated using equation S12, is for a negative anodic current. 


\section{Simulated Voltammetry Varying Droplet Radius and Contact Angle.}

Figure S9 shows cyclic voltammograms from finite-element simulations where the droplet radius and the contact area between the electrode and the droplet were varied.
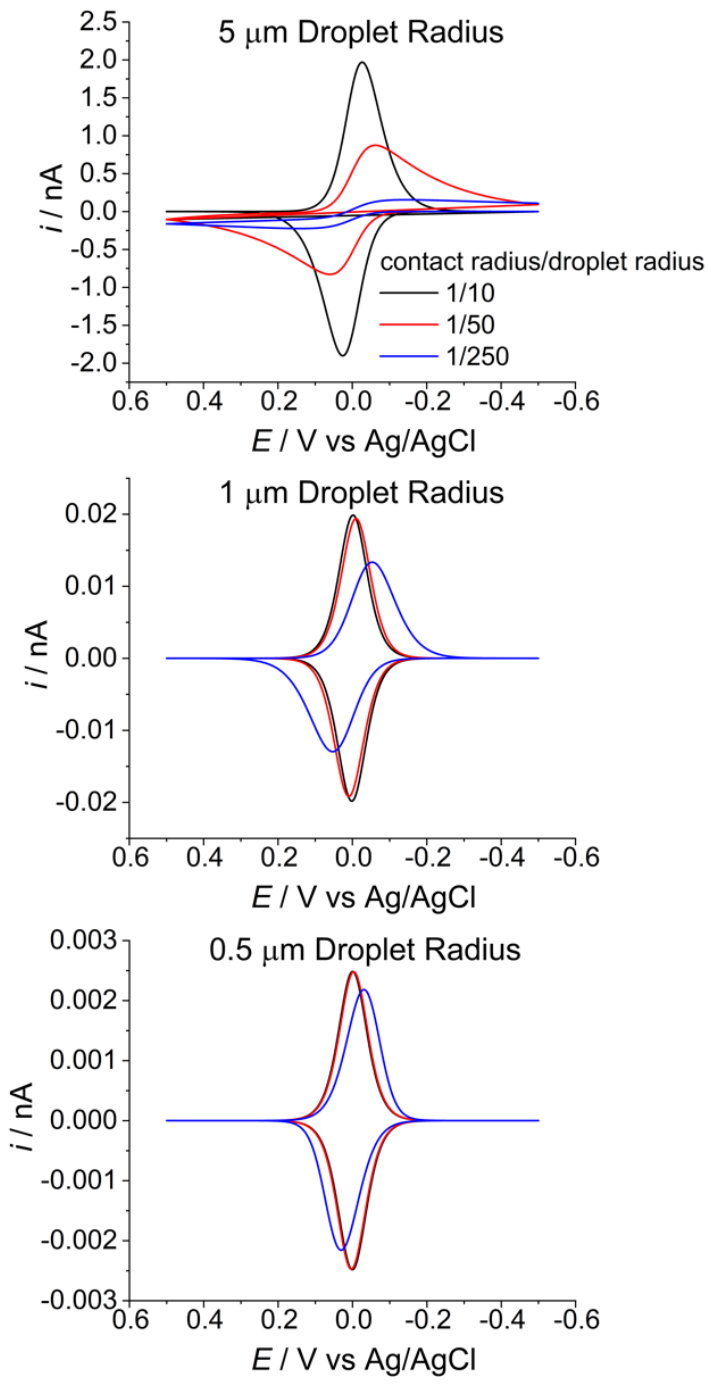

Figure S9. Simulated cyclic voltammograms for different contact areas between the droplet and the electrode as well as different droplet radii. (a) Cyclic voltammetry with a $5 \mu \mathrm{m}$ radius droplet, (b) $1 \mu \mathrm{m}$ radius droplet and, (c) $0.5 \mu \mathrm{m}$ radius droplet. The different voltammograms in each figure are from different contact areas where black shows a 1/10 ratio between the contact area radius and the droplet radius, red shows a $1 / 50$ ratio, and blue shows a $1 / 250$ ratio. $v=100 \mathrm{mV} / \mathrm{s}$.

Figure S9 shows that the voltammetric wave from voltammetry of droplets qualitatively varies depending on electrode contact area for larger droplets $(>1 \mu \mathrm{m})$ more than for smaller droplets $(<1 \mu \mathrm{m})$. Droplets with a radius less the $500 \mathrm{~nm}$ show voltammetric characteristics that are nearly independent of the contact area unless the contact area radius is less than 1/250 the droplet radius, i.e., less than $2 \mathrm{~nm}$. 


\section{Simulated Voltammetry Varying the Electron-Transfer Rate Kinetics}

Figure S10a shows simulated cyclic voltammograms of a $\mathrm{H}_{2} \mathrm{O}$ droplet containing $50 \mathrm{mM}\left[\mathrm{Fe}(\mathrm{CN})_{6}\right]^{4-}$, where the electron transfer rate kinetics $\left(k_{0}\right)$ of the $\left[\mathrm{Fe}(\mathrm{CN})_{6}\right]^{4-} /\left[\mathrm{Fe}(\mathrm{CN})_{6}\right]^{3-}$ reaction were varied. Slower rate kinetics result in peak splitting similar to what was experimentally observed in Figure S3 when $\mathrm{TBACl}$ or $\mathrm{TBABF}_{4}$ was the electrolyte in the DCE phase. Figure S10b shows an overlay of the experimental result from Figure 2 when TBACl was the electrolyte in the DCE phase, with a simulated voltammogram $\left(\mathrm{k}^{0}=7 \times 10^{-3} \mathrm{~cm} / \mathrm{s}\right)$. This $k_{0}$ value was chosen such that the simulated peak currents matched with the experimental peak currents.
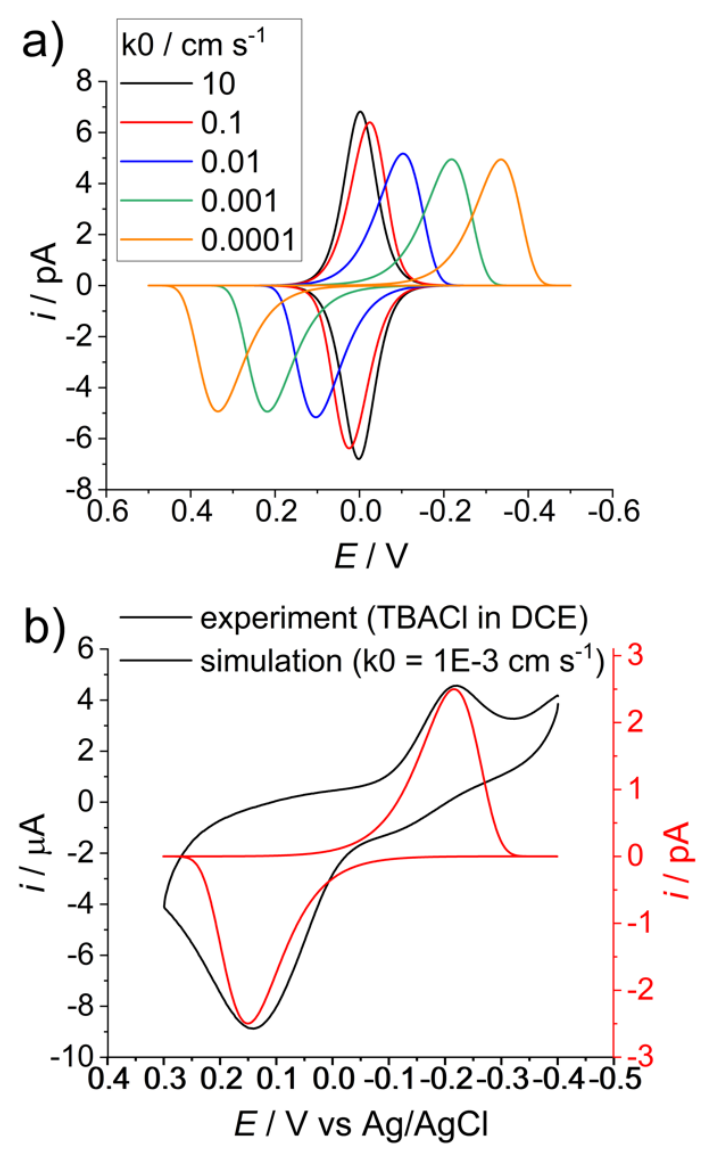

Figure S10. Simulated voltammetry of a $\mathrm{H}_{2} \mathrm{O}$ droplet where $k_{0}$ was varied. a) A set of simulated voltammograms with different $k_{0}$ values for the $\left[\mathrm{Fe}(\mathrm{CN})_{6}\right]^{4-} /\left[\mathrm{Fe}(\mathrm{CN})_{6}\right]^{3-}$ reaction. $\mathrm{The}_{2} \mathrm{O}$ phase contained $50 \mathrm{mM}\left[\mathrm{Fe}(\mathrm{CN})_{6}\right]^{4-}$. b) Comparison of the experimental cyclic voltammogram from Figure 2 of the main text, and a simulated cyclic voltammogram where the $k_{0}$ value was $7 \times 10^{-3} \mathrm{~cm} / \mathrm{s} . v=50 \mathrm{mV} / \mathrm{s}$ for each voltammogram. 


\section{Voltammetry of $\mathrm{TBA}_{x} \mathrm{~K}_{3-\mathrm{x}} \mathrm{Fe}(\mathrm{CN})_{6}$ in $\mathrm{DCE}$}

The solubility of $\left[\mathrm{Fe}(\mathrm{CN})_{6}\right]^{3-}$ in the DCE phase was investigated by the addition of $50 \mathrm{mM}\left[\mathrm{Fe}(\mathrm{CN})_{6}\right]^{3-}$ and varying amounts of TBACl to a 2/1 DCE/water mixture. The DCE phase contained $0.1 \mathrm{M} \mathrm{TBAClO}_{4}$. Upon mixing of the two phases, a yellow color was apparent in the DCE phase as $\mathrm{TBA}_{x} \mathrm{~K}_{3-\mathrm{x}} \mathrm{Fe}(\mathrm{CN})_{6}$ partitioned into the DCE due to the presence of $\mathrm{TBA}^{+}$cations in the aqueous phase. Control experiments showed that no appreciable amount of $\left[\mathrm{Fe}(\mathrm{CN})_{6}\right]^{3-}$ partitioned in the absence of TBACl. The DCE phase was extracted and voltammetry was used to quantify the relative amount of $\mathrm{TBA}_{x} \mathrm{~K}_{3-\mathrm{x}} \mathrm{Fe}(\mathrm{CN})_{6}$ (Figure $\mathrm{S} 11)$. It is apparent that as the concentration of TBACl increased, the degree of partitioning of $\mathrm{TBA}_{\mathrm{x}} \mathrm{K}_{3-}$ ${ }_{x} \mathrm{Fe}(\mathrm{CN})_{6}$ increased accordingly. The $3^{\text {rd }}$ cycle of each voltammogram is shown, but the reversibility was continuous throughout all scans. Significantly, the $E_{1 / 2}$ for $\mathrm{TBA}_{x} \mathrm{~K}_{3-\mathrm{x}} \mathrm{Fe}(\mathrm{CN})_{6}$ reduction in DCE is -0.323 $\mathrm{V}$, around $0.6 \mathrm{~V}$ shifted from the $E_{1 / 2}$ in aqueous systems.

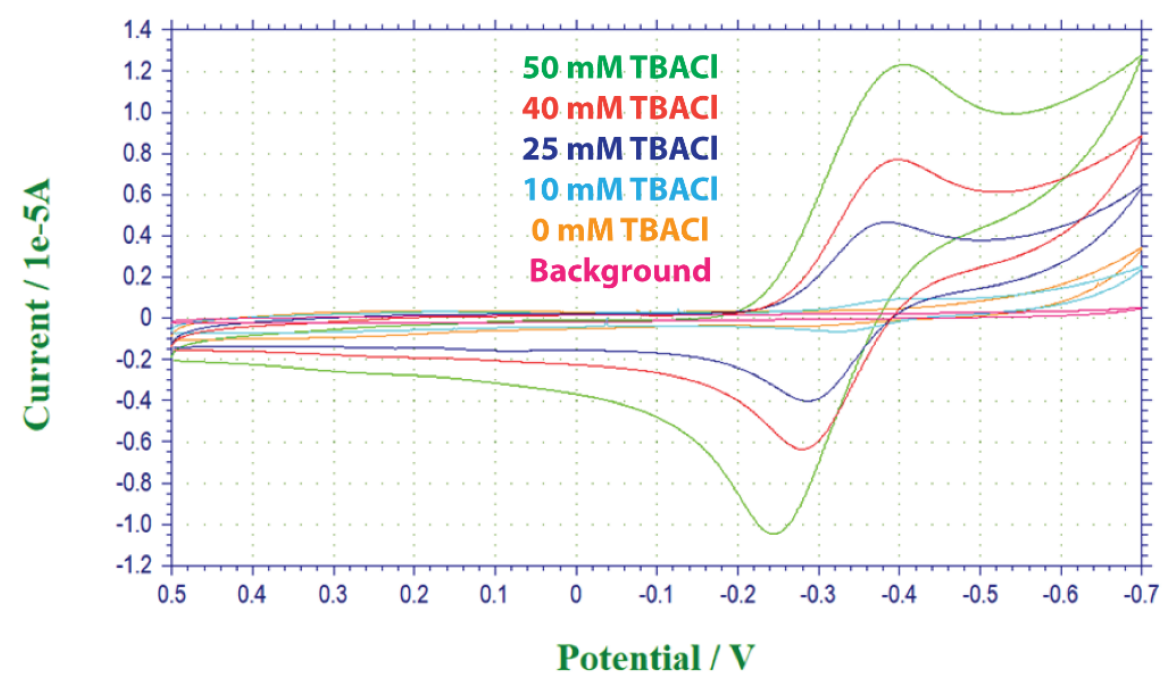

Figure S11. Voltammetry of $\mathrm{TBA}_{\mathrm{x}} \mathrm{K}_{3-\mathrm{x}} \mathrm{Fe}(\mathrm{CN})_{6}$ in DCE. Increasing peak currents correspond to increasing $\mathrm{TBACl}$ concentrations initially dissolved in the aqueous phase contributing to increased partitioning of $\mathrm{TBA}_{\mathrm{x}} \mathrm{K}_{3-\mathrm{x}} \mathrm{Fe}(\mathrm{CN})_{6}$ into the bulk DCE phase. $v=100 \mathrm{mV} / \mathrm{s}$ for each voltammogram. A gold macroelectrode $(\mathrm{r}=1.5 \mathrm{~mm})$, platinum wire, and $\mathrm{Ag} / \mathrm{AgCl}$ reference electrode connected to the solution by an agarose salt bridge were used as the working, counter, and reference electrodes, respectively. 
13. Pt Disk Electrode vs Glassy Carbon Disk Electrode in $\mathrm{H}_{2} \mathrm{O}$ with $5 \mathrm{mM}$ Potassium Ferrocyanide.

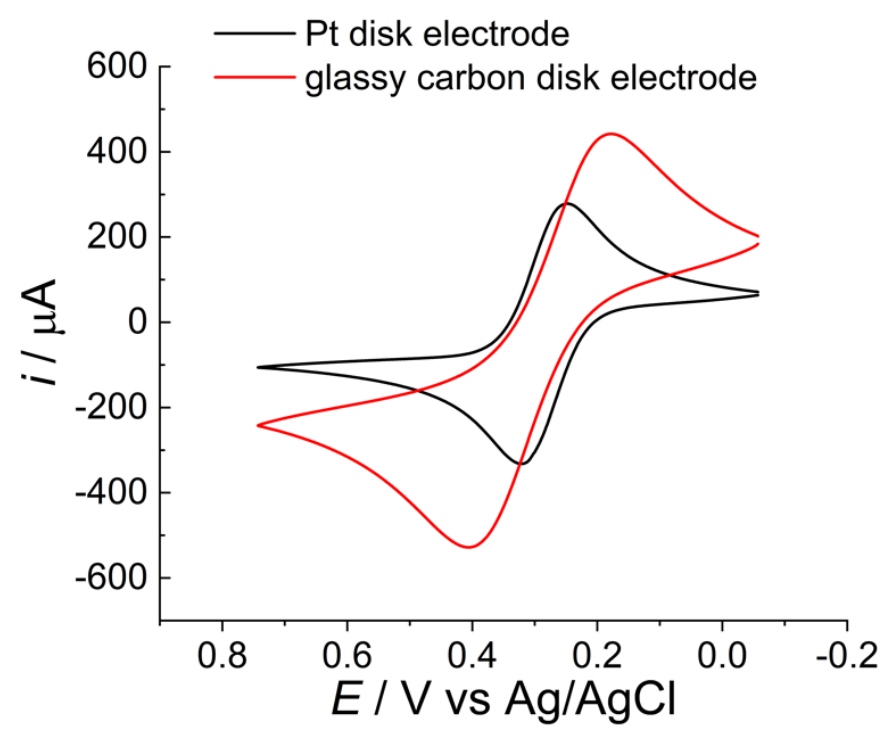

Figure S12. The voltammetric response for a $\sim 1 \mathrm{~mm}$ Pt disk electrode (black) and a $\sim 1.5 \mathrm{~mm}$ glassy carbon disk electrode (red) placed in $\mathrm{H}_{2} \mathrm{O}$ containing $50 \mathrm{mM} \mathrm{K} 4\left[\mathrm{Fe}(\mathrm{CN})_{6}\right]$. The $\mathrm{H}_{2} \mathrm{O}$ phase was in contact with a DCE phase containing $0.1 \mathrm{M} \mathrm{TBAClO}_{4}$ where the $\mathrm{Ag} / \mathrm{AgCl} \mathrm{RE}$ was placed. $v=100 \mathrm{mV} / \mathrm{s}$. The $2^{\text {nd }}$ cycle is shown for each voltammogram.

In order to test the dependence of the $\left[\mathrm{Fe}(\mathrm{CN})_{6}\right]^{3-14-}$ couple on the electrode material, the voltammetric response for the reaction was measured using a Pt disk electrode $(\mathrm{r} \sim 1 \mathrm{~mm})$ and a GC disk electrode $(\mathrm{r} \sim 1.5 \mathrm{~mm})$, shown in Figure S12. The results show that the $E_{1 / 2}$ for the reaction on $\mathrm{Pt}$ vs glassy carbon does not change, however, there is an increase in current peak splitting for the glassy carbon electrode. This is indicative of slower reaction kinetics on the glassy carbon surface compared to the $\mathrm{Pt}$ surface. The $E_{1 / 2}$ for $\left[\mathrm{Fe}(\mathrm{CN})_{6}\right]^{3-4-}$ couple with the Pt disk electrode was $0.286 \mathrm{~V}$ and with the glassy carbon electrode was $0.292 \mathrm{~V}$. The larger peak currents for the glassy carbon electrode are due to the larger disk radius. The red curve for the glassy carbon electrode was also used in Figure $2 \mathrm{~b}$ of the main text. 


\section{References.}

1. Peljo, P.; Girault, H. H., Electrochemistry at Liquid/Liquid Interfaces. John Wiley \& Sons, Ltd: Encyclopedia of Analytical Chemistry, 2012.

2. Gschwend, G. C.; Olaya, A.; Girault, H. H., How to Polarise an Interface with Ions: The Discrete Helmholtz Model. Chem. Sci. 2020.

3. Konopka, S. J.; McDuffie, B., Diffusion Coefficients of Ferri- and Ferrocyanide Ions in Aqueous Media, Using Twin-Electrode Thin-Layer Electrochemistry. Anal. Chem. 1970, 42 (14), 1741-1746.

4. Kim, B. K.; Boika, A.; Kim, J.; Dick, J. E.; Bard, A. J., Characterizing Emulsions by Observation of Single Droplet Collisions-Attoliter Electrochemical Reactors. J. Am. Chem. Soc. 2014, 136 (13), 4849-4852. 